barriers and facilitators that may affect the integration and scale-up of evidence-based safer conception programs from high-resource countries. Furthermore, these implementation studies will identify the adaptable program components to ensure cost-effective and sustainable services in low-resource settings. From a reproductive justice perspective, HIV prevention programs should include accessible safer conception services for HIV-affected couples. Financial support needed to achieve this goal may require commitment from foundations and national and global organizations to strengthen HIV prevention efforts and assure the reproductive rights of HIV-affected couples.

\section{Conflict of interest}

OM has been a paid consultant for the World Health Organization. VKD has been a paid consultant for Bayer Healthcare Pharmaceuticals and the University of California, San Francisco.

\section{References}

[1] Brubaker S, Bukusi E, Odoyo J, Okumu A, Cohen CR. Pregnancy and HIV transmission among HIV-discordant couples in clinical trials in Kisumu, Kenya. HIV Med 2011;12(5):316-21.

[2] World Health Organization. Guidance on oral pre-exposure prophylaxis (PrEP) for serodiscordant coupes, men and transgender women who have sex with men at high risk of HIV. Geneva: WHO; 2012. http://www.who.int/hiv/pub/ guidance_prep/en/.

[3] Chadwick RJ, Mantell JE, Moodley J, Harries J, Zweigenthal V, Cooper D. Safer conception interventions for HIV-affected couples: implications for resource constrained settings. Top Antivir Med 2011;19(4):148-55

[4] Moragianni VA. Why are we still, 20 years later, depriving HIV-serodiscordant couples of equal access to fertility care? Fertil Steril 2014;102(2):352-3.
[5] Baeten JM, Donnell D, Ndase P, Mugo NR, Campbell J, Wangisi J, et al. Antiretroviral prophylaxis for HIV prevention in heterosexual men and women. $\mathrm{N}$ Engl J Med 2012;367(5):399-410.

[6] Cohen MS, Chen YQ, McCauley M, Gamble T, Hosseinipou MC, Kumarasamy N, et al. Prevention of HIV-1 infection with early antiretroviral therapy. N Engl J Med 2011;365(6):493-505.

[7] Vernazza PL, Graf I, Sonnenberg-Schwan U, Geit M, Meurer A. Preexposure prophylaxis and timed intercourse for HIV-discordant couples willing to conceive a child. AIDS 2011;25(16):2005-8.

[8] Auvert B, Taljaard D, Lagarde E, Sobngwi-Tambekou J, Sitta R, Puren A. Randomized, controlled intervention trial of male circumcision for reduction of HIV infection risk: the ANRS 1265 trial. PLoS Med 2005;2(11):e298.

[9] Bailey RC, Moses S, Parker CB, Agot K, Maclean I, Krieger JN, et al. Male circumcision for HIV prevention in young men in Kisumu, Kenya: a randomised controlled trial. Lancet 2007;369(9562):643-56.

[10] Gray RH, Kigozi G, Serwadda D, Makumbi F, Watya S, Nalugoda F, et al. Male circumcision for HIV prevention in men in Rakai, Uganda: a randomized trial. Lancet 2007;369(9562):657-66

[11] Semprini AE, Levi-Setti P, Bozzo M, Ravizza M, Taglioretti A, Sulpizio P, et al. Insemination of HIV-negative women with processed semen of HIV-positive partners. Lancet 1992;340(8831):1317-9.

[12] Semprini AE, Macaluso M, Hollander L, Vucetich A, Duerr A, Mor G, et al. Safe conception for HIV-discordant couples: insemination with processed semen from the HIV-infected partner. Am J Obstet Gynecol 2013;208(5):402.e1-9.

[13] Ohl J, Partisani M, Wittemer C, Schmitt MP, Cranz C, Stoll-Keller F, et al. Assisted reproduction techniques for HIV serodiscordant couples: 18 months of experience. Hum Reprod 2003;18(6):1244-9.

[14] Sauer MV, Wang JG, Nataki CD, Nakhuda GS, Vardhan P, Jovanovic V, et al. Providing fertility care to men seropositive for human immunodeficiency virus: reviewing 10 years of experience and 420 consecutive cycles of in vitro fertilization and intracytoplasmic sperm injection. Fertil Steril 2009;91(6):2455-60.

15] Sauer M, Chang P. Establishing a clinical program for human immunodeficiency virus 1-seropositive men to father seronegative children by means of in vitro fertilization with intracytoplasmic sperm injection. Am J Obstet Gynecol 2002;186(4):627-33.

[16] Mmeje O, Cohen CR, Murage A, Ong'ech J, Kiarie J, van der Poel S. Promoting reproductive options for HIV-affected couples in sub-Saharan Africa. BJOG 2014in press.

\title{
Blood salvage device for use during ruptured ectopic pregnancy in low-resource countries
}

\author{
Caitlin O. Winget ${ }^{\mathrm{a}}$, Theresa K. Fisher ${ }^{\mathrm{b}}$, Rajen N. Kumar ${ }^{\mathrm{b}}$, Alexander H. Harrington ${ }^{\mathrm{c}}$, Gillian E. Henker ${ }^{\mathrm{b}}$, \\ Robertson D. Davenport ${ }^{\mathrm{d}}$, Alexander T. Odoi ${ }^{\mathrm{e}}$, Kathleen H. Sienko a,b,*
}

${ }^{a}$ Department of Biomedical Engineering, University of Michigan, Ann Arbor, MI, USA

${ }^{\mathrm{b}}$ Department of Mechanical Engineering, University of Michigan, Ann Arbor, MI, USA

c Department of Sociology, University of Michigan, Ann Arbor, MI, USA

d Department of Pathology, University of Michigan, Ann Arbor, MI, USA

e Department of Obstetrics and Gynecology, Kwame Nkrumah University of Science and Technology, Kumasi, Ghana

\section{A R T I C L E I N F O}

\section{Article history:}

Received 14 April 2014

Received in revised form 19 July 2014

Accepted 17 September 2014

\section{Keywords:}

Blood salvage

Blood transfusion

Implementation engineering

Low-resource countries

Maternal health

Medical device design

Ruptured ectopic pregnancy

\footnotetext{
* Corresponding author at: University of Michigan, 2350 Hayward St., 2650 G.G. Brown, Ann Arbor, MI 48109, USA. Tel.: + 7346478249.
}

E-mail address: sienko@umich.edu (K.H. Sienko).
Obstetric hemorrhage, the leading cause of maternal mortality, accounts for up to $44 \%$ of maternal deaths in regions of West and East Sub-Saharan Africa; $26 \%$ of these deaths can be attributed to the paucity of donated blood available for emergency transfusions [1]. This situation complicates the efforts of clinicians to treat ruptured ectopic pregnancy, which is the largest contributor to mortality in the first trimester. Autotransfusion is a life-saving intraoperative blood salvage procedure that is routinely performed using automated blood salvage devices in high-income countries [2]. Such devices are inappropriate for low-income countries owing to their cost and complexity (i.e. difficult to maintain), among other factors [3]. Furthermore, effective manual blood salvage solutions including the soup ladle method [4] and the Tanguieta funnel [3] developed for use in low-income countries can be labor intensive and require numerous disposables.

Design ethnography studies including clinical observations and interviews were conducted primarily at Komofo Anokye Teaching 

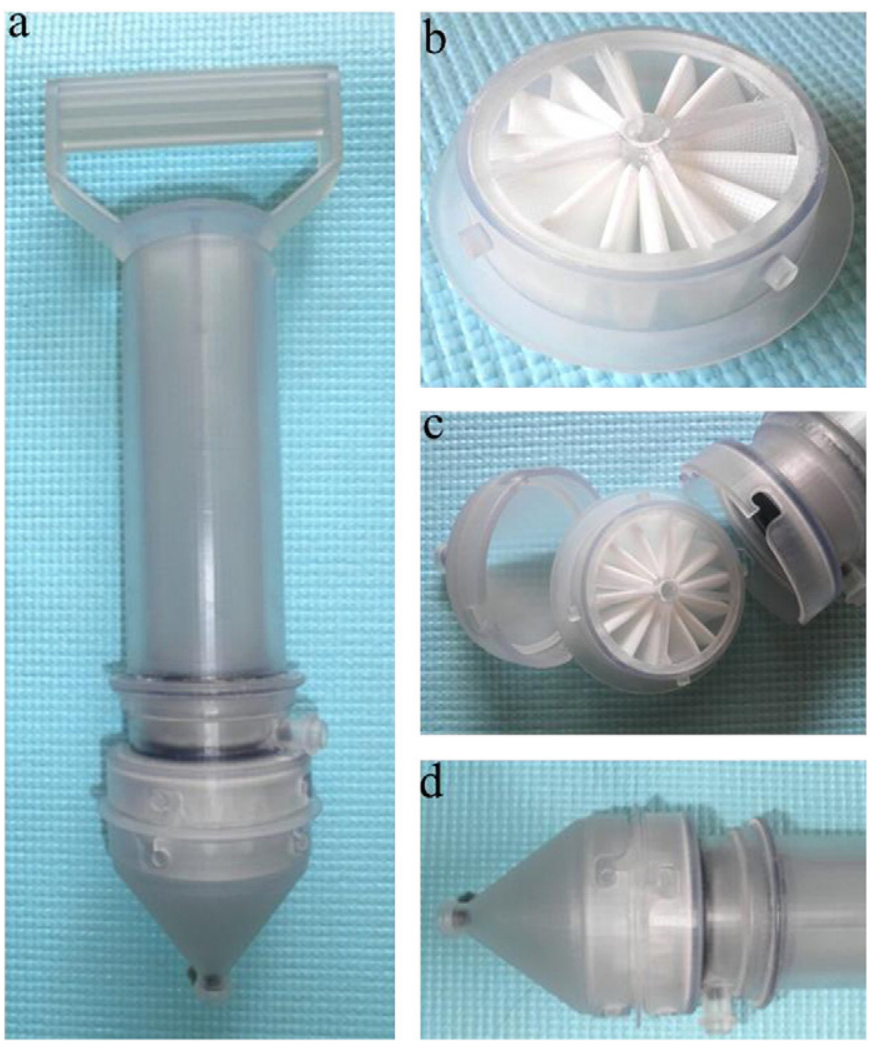

Fig. 1. (A) Gross specimens of recurrent abdominopelvic disease, showing well-circumscribed, nodular lesions. (B) Pathologic evaluation of abdominopelvic tumor nodules (hematoxylin-eosin x40) showing spindle cells with occasionally enlarged nuclei with mild atypia. No necrosis or mitoses identified consistent with LGL. Inset showing diffuse strong positive nuclear staining for estrogen receptor. Progesterone receptor staining was negative (not shown).

Hospital, Kumasi, Ghana, and several nearby district hospitals during July and August 2010. The aim was to identify and understand the need for a simple, low-cost, closed-system and mechanical alternative for use during an intraoperative blood salvage procedure following a ruptured ectopic pregnancy. User requirements and engineering specifications were determined through interviews with Ghanaian clinicians, nurses, and biomedical technicians; observations; benchmarking; literature review; and surveys. Solution concepts were generated using functional decomposition and brainstorming techniques.

The selected concept resembled an oversized syringe that served as a self-contained, mechanically powered system with a series of one-way valves, inline filters, and an outlet valve connected to a standard blood bag (Fig. 1). The instrument is operated by inserting the nozzle into the pooling blood present within the surgically opened abdominal cavity. Pulling back on the plunger draws the pooled blood inside, passing it through a 170- $\mu$ m filter (Fig. 1b) and into the barrel. The nozzle is typically positioned within the abdominal cavity to avoid regions with large clots. However, clots entering the device accumulate in the hollowed nozzle. Pushing down on the plunger then forces the blood to exit through a one-way valve that can be connected to a standard blood bag. The operation repeats until all of the blood intended for transfusion is processed. The current version of the concept solution includes a disposable filter (Fig. 1c) that is replaced between each patient use.
The other components of the device can be sterilized in an autoclave. Although the filter medium is autoclavable, the filter's pore size makes it difficult to clean, thereby increasing the likelihood of cross-contamination. The prototype (Fig. 1a) weighs approximately $0.5 \mathrm{~kg}$ with overall dimensions of $33 \times 11 \times 7.5 \mathrm{~cm}$ and features transparent components to allow observation of the blood. Each filter cartridge has $170-\mu \mathrm{m}$ pores and a surface area of $137 \mathrm{~cm}^{2}$. The nozzle opens to replace the filter by twisting a four-prong bayonet closure (Fig. 1d).

Pre-clinical studies were performed to evaluate the prototype. Institutional Review Board approval was not obtained for the pre-clinical studies because the studies did not involve human subjects. Simulated blood was used to confirm processing rates of 1.6-2.6 L/ min. Five test samples of reconstituted human blood (approximately $500 \mathrm{~mL}$ packed red blood cells and ABO-compatible thawed plasma, approximately $50 \%$ hematocrit) were used to assess the effects of processing on hematocrit and plasma hemoglobin levels. The samples showed no evidence of hemolysis or changes in hematocrit or hemoglobin. The concept was also well received by Ghanaian clinicians following informal usability studies. Although Ghanaian stakeholders originally requested a more cost-effective automated blood salvage device, design ethnography studies revealed challenges associated with maintaining such systems in low-income countries.

This concept solution has the potential to address the need for a low-cost, mechanical device to treat ruptured ectopic pregnancy. Future work includes conducting additional pre-clinical studies, obtaining regulatory approval, performing clinical trials in Ghana, and iterating the design to further reduce the cost of the device (target US $\$ 1$ per use). Simplicity of design as well as intuitive design features should increase the likelihood of minimal required training and adoption by clinics lacking a reliable power supply or the funds to purchase and maintain complex equipment.

\section{Acknowledgments}

This work was supported by the National Collegiate Inventors and Innovators Alliance (Program Grant \#7251-09 “Development of an Undergraduate Minor Specialization in Sustainable Global Health Design"), National Collegiate Inventors and Innovators Alliance e-Team grant (Program Grant \#8751-11 "Design Innovations for Infants and Mothers Everywhere (DIIME)"), and the University of Michigan College of Engineering, Ann Arbor, USA.

\section{Conflict of interest}

C.O. Winget, T.K. Fisher, R.N. Kumar, A.H. Harrington, and G.E. Henker have filed a patent application for the fluid filtering device and method described in this study and C.O. Winget, T.K. Fisher, R.N. Kumar, and G.E. Henker have equity interest in DIIME (Grand Rapids, MI, USA) a for-profit social venture.

\section{References}

[1] Bates I, Chapotera GK, McKew S, van den Broek N. Maternal mortality in sub-Saharan Africa: the contribution of ineffective blood transfusion services. BJOG 2008;115(11):1331-9.

[2] Selo-Ojeme DO, Onwude JL, Onwudiegwu U. Autotransfusion for ruptured ectopic pregnancy. Int J Gynecol Obstet 2003;80(2):103-10.

[3] Priuli G, Darate R, Perrin RX, Lankoande J, Drouet N. Multicentre experience with a simple blood salvage technique in patients with ruptured ectopic pregnancy in sub-Sahelian West Africa. Vox Sang 2009;97(4):317-23.

[4] Ansaloni L, Gaines C, Tocalli E. “Soup ladle” autotransfusion. Br J Surg 1996;83(1): 104. 